\title{
Hannes Bezzel
}

\section{Saul}

\author{
Israels König in Tradition, Redaktion und früher Rezeption
}

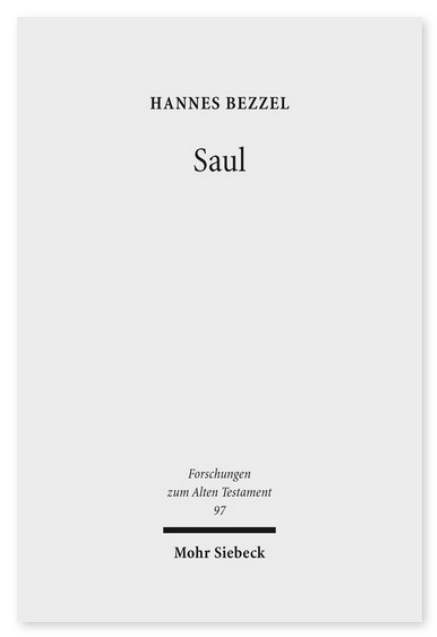

2015. XII, 303 Seiten. FAT 97

ISBN 978-3-16-153685-4 DOI 10.1628/978-3-16-153685-4 eBook PDF 119,00€

ISBN 978-3-16-153684-7

Leinen $119,00 €$
In dieser Studie fragt Hannes Bezzel nach Saul, dem ersten König Israels, nicht als einer historischen Gestalt der »frühen Königszeit«, sondern als literarischer Person, deren Entwicklung er diachron in den Blick nimmt. Einsatzpunkt ist die »frühe Rezeptionsgeschichte« bis zum Ende des ersten nachchristlichen Jahrhunderts. An den jeweils unterschiedlichen Saulbildern im Väterlob Ben Siras, in Qumran (besonders in 4Q252), im Liber Antiquitatum Biblicarum und in den Antiquitates Judaicae des Flavius Josephus arbeitet Bezzel Motive und Methoden des interpretierenden Umgangs mit der ambivalenten Gestalt Sauls heraus, die denen »innerbiblischer « Rezeptionsprozesse vergleichbar sind. Von hier ausgehend wird das Phänomen der »rewritten Bible / scripture » zunächst in die Chronik, dann in die Redaktionsgeschichte der Samuelbücher hinein weiter verfolgt. In seiner Analyse findet Hannes Bezzel eine ältere Saulüberlieferung in I Sam 9-10,16*; 11*; 14,47-51*. Der junge Benjaminit wird von einem Gottesmann auf eine Heldentat vorbereitet, schlägt die Ammoniter, wird König und als solcher retrospektiv mit einem rundweg positiven Nachruf bedacht. Im Rahmen eines erweiterten Samuel-Saul-Kranzes (I Sam 1*; 4*; 9-10,16*; 13-14*; 29*; 31*) wurde über die Figur Samuels mit der Ladeüberlieferung und einer Geschichte über Jonatan die Philisterthematik eingeführt. Auch gegen sie ist Saul zunächst im Kampf erfolgreich, er stirbt jedoch samt seinen Söhnen auf Gilboa. Erst in einem dritten Schritt wurde dieser Erzählkranz im Kontext der »Aufstiegsgeschichte« mit der Davidüberlieferung verbunden. Ab jetzt steht die geschichtstheologische Frage im Raum, warum der erste König Israels, obwohl Gesalbter JHWHs, nicht von seinem Sohn, sondern von David beerbt wurde.

Hannes Bezzel Born 1975; 2007 Dr. theol. (Göttingen); 2014 Habilitation (Jena); since 2015 Professor of Old Testament a Friedrich Schiller University Jena.

https://orcid.org/0000-0002-2117-4005

Jetzt bestellen:

https://mohrsiebeck.com/buch/saul-9783161536854?no_cache=1

order@mohrsiebeck.com

Telefon: +49 (0)7071-923-17

Telefax: $+49(0) 7071-51104$ 